\title{
Agricultura familiar no Alto Guaporé (MT), Brasil: rendas não agrícolas como estratégia de adaptação às mudanças ambientais
}

\author{
Heitor Marcos Kirsch \\ Universidade do Estado de Mato Grosso, Pontes e Lacerda, Brasil. \\ Email: heitor.kirsch@gmail.com \\ Eduardo Ernesto Filippi \\ Universidade Federal do Rio Grande do Sul, Porto Alegre, Brasil. \\ Email: edu_292000@yahoo.com.br
}

\begin{abstract}
Resumo: Esse trabalho analisa a capacidade adaptativa de um grupo de agricultores familiares cuja subsistência é baseada em rendas não agrícolas, diante das transformações que ocorreram no uso e na gestão do ambiente.Para demonstrar que a vulnerabilidade diante de tais mudanças possui uma dimensão social e é contingente às condições do funcionamento do ambiente institucional, aspectos frequentemente negligenciados na literatura sobre o problema, foi aplicado um questionário semiestruturado composto por questões que objetivavam retratar as condições sociais, econômicas, produtivas, ambientais e institucionais às quais estão submetidas para mobilizar e viabilizar sua reprodução social.As iniciativas mobilizadas por essas famílias para viabilizaremsua subsistência demonstram que a capacidade de se adaptar é desigual, apontando que os fatores sociais são determinantes e fundamentais da capacidade de adaptação em todas as escalas.

Palavras-chave: Vulnerabilidade, mudanças ambientais globais, estratégias de produção, agricultura Familiar.
\end{abstract}

\section{Agricultura familiar en Alto Guaporé (MT), Brasil: rentas no agrícolas como estrategia de adaptación a los cambios ambientales}

Resumen: Este trabajo analiza la capacidad adaptativa de un grupo de agricultores familiares cuya subsistencia se basa en rentas no agrícolas, ante las transformaciones que ocurrieron en el uso y la gestión del medio ambiente. Para demostrar que la vulnerabilidad ante estos cambios tiene una dimensión social y es contingente a las condiciones del funcionamiento del ambiente institucional, aspectos frecuentemente descuidados en la literatura sobre el problema, se aplicó un cuestionario semiestructurado compuesto por cuestiones que objetivaban retratar las condiciones sociales, económicas, productivas, ambientales e institucionales a las que están sometidas para movilizar y viabilizar su reproducción social. Las iniciativas movilizadas por esas familias para viabilizar su subsistencia demuestran que la capacidad de adaptarse es desigual, apuntan- 
do que los factores sociales son determinantes y fundamentales de la capacidad de adaptación en todas las escalas.

Palabras clave: Vulnerabilidad, cambio ambiental global, estrategias de producción, agricultura familiar.

\title{
Family farming in Alto Guaporé (MT), Brazil: non-agricultural incomes as an adaptation strategy to environmental changes
}

\begin{abstract}
This paper analyses the adaptive capacity of a group of family farmers whose livelihoods are based on non-agricultural income from social transfers in the face of changes caused by global environmental changes. There is a long history of adapting to their impacts, managing the risks and dangers of their consequences. In order to demonstrate that vulnerability has a social dimension and is contingent on the conditions of the functioning of the institutional environment, aspects frequently neglected in the literature on the problem, a semi-structured questionnaire was applied consisting of questions that aimed to portray the social, economic, productive, environmental and institutional conditions to which they are subject in order to mobilize and make their social reproduction viable. The initiatives mobilized by these families to make their livelihoods viable demonstrate that the capacity to adapt is unequal, pointing out that social factors are determinants and fundamental to the capacity to adapt at all scales.
\end{abstract}

Key words: Vulnerability, global environmental changes, production strategies, family farming

$* * *$

\section{Introdução}

Ainda que se reconheça que o processo de desenvolvimento emergente a partir da segunda metade do século XX contribuiu para resultados significativamente positivos, em termos de melhoria do bem-estar humano e econômico neste período, sua generalização ainda é um desafio que têm sido objeto de atenção nas agendas de pesquisa e de políticas públicas em várias sociedades. A pobreza, a fome e a desigualdade ainda são uma realidade que atinge uma parcela bastante significativa da população mundial(Hardoon, 2017; Sumner, 2010).Adicionalmente, com a rápida e profunda transformação dos ecossistemas em praticamente todas as partes do mundo em virtude desse processo, vários estudiosos passaram a chamara atenção para um desafio que, segundo eles, merece ser tratado comoprioritário: alcançar o desenvolvimento com sustentabilidade. Em grande medida, isso decorre da constatação que nesse período houve um custo crescente no que tange à degradaç̧ão da maioria dos serviços dos ecossistemas, com severas mudanças nos regimes e nos principais aspec- 
tos das dinâmicas associadas aos sistemas geofísicos planetários (Gunderson \& Folke, 2011; Rockström et al., 2009).

A velocidade e a extensão da ação humana na modificação do meio natural produziramdesequilíbrios emníveis que causam uma crescente inquietação até mesmo sobre as condições para sua irreversibilidade em termos globais (Bai et al., 2015; Biermann et al., 2012).As distintas formas de uso e de manejo da terra para produzir os mais diferentes bens e serviços representarama mais profunda alteração humana sobre a superfície terrestre, numa relação quase sempre negativamente impactante em termos de consequências ambientais sobre a biodiversidade, nos ciclos dos nutrientes e na estrutura dos solos (Fischer et al., 2007; Foley et al., 2005).

Alguns autores chamam a atenção para o fato de que o desmatamento de novas áreas, sobretudo as destinadas para a atividade agrícola, algumas delas com solos bastante frágeis, têm ocasionado uma redistribuiçã̃o dos regimes de chuvas regionais e da evapotranspiração, tanto local quanto global e nos regimes de temperaturas médias (Costa \& Pires, 2010; D’Almeida et al., 2007). No Brasil, alterações nesses ciclos em regiões como a bacia Amazônica e o Cerrado brasileiro têm sido associados aos processos de degradação, de erosão e perda da fertilidade natural e/ou a estresses hídricos em suas áreas onde se pratica a agricultura (Foley et al., 2007; Gordon, Peterson, \& Bennett, 2008; Nobre, Sellers, \& Shukla, 1991).

Tais transformações tem o potencial de reduzir inesperadamente ou frustrar as colheitas agrícolas, ou, até mesmo, deslocar vários cultivos das localidades climaticamente favoráveis, até o momento, para outras onde não se observa sua ocorrência (EMBRAPA \& UNICAMP, 2008). A fim de mitigar ou evitar os efeitos negativos destas transformações, foi dispensadoum significativo esforço ao longo das últimas décadasà uma crescente compreensão dos padrões da mudança ambiental e da dinâmica dos sistemas terrestres, particularmente em torno do clima. Seu objetivo foi o gerenciamento dos riscos e dos perigos sobre as dimensões físicas do problema, sobretudo os associados à agricultura. Portanto, a noção de vulnerabilidade ante essas transformações é compreendida como o resultado residual, em termos negativos, da suscetibilidade e incapacidade que as pessoas possuem em lidar com a exposição aos riscos e perigos e os efeitos adversos resultantes da mudança nos regimes naturais (Adger, 2006).

Neste artigo, argumentamos que esse entendimento acerca da vulnerabilidade, sobretudo das pessoas, ante às transformações do meio natural é demasiado restrito. Asimples identificação e o gerenciamento das perturbações e dos estressores são insuficientes para compreender os impactos e as respostas diferenciais dos sistemas ou dos seus componentes quando estes são afetados. O motivo para que isso ocorraé porque não se considera a estrutura da sequência causal da situação do perigo.

O modelo conceitual de vulnerabilidade desenvolvido nesse trabalho busca compreender os processos mobilizados para o enfrentamento ou 
para a adaptação, particularmente nos grupos sociais familiares em ambientes rurais. Em outras palavras, se enfatiza as dimensões sociais da vulnerabilidade. Nessa perspectiva, o risco é analisado em função da sensibilidade e da exposição dos sistemas, mas somente assume essa característica quando há o entendimento de que são fenômenos mediados pelo ambiente organizacional e institucional. Além do mais, os processos de adaptação ou de enfrentamento das mudanças ambientais contemporâneas são as expressões das ações reflexivas que os indivíduos desenvolvem. Eles derivam de uma aprendizagem individual e/ou coletiva, sobretudo, em momentos de eventos extremos ou situações de crise, sempre mediados pelo conjunto de instituições e pelas relações sociais e culturais que atuam em diferentes níveis numa localidade e que estão situados em um contexto específico (Ellis, 1998).

Esses conceitos são aplicados ao estudo empírico desenvolvido na região do Alto Guaporé, no sudoeste do estado de Mato Grosso, no Brasil. Os resultados da investigação demonstram que a vulnerabilidade ou a capacidade de resistir e enfrentar dos agricultores familiares às profundas mudanças ambientais que ocorreram ao longo das últimas décadas, sobretudo no uso e gestão dos solos e dos recursos hídricos, não são noções que refletem meramente a dimensão a exposição física aos riscos e perigos dessas pessoas. A capacidade dos indivíduos ou grupos em se adequarem aosnovos cenários, se modifica ao longo do tempo e é diferenciada entre e dentro dos grupos, dependendo de sua posição institucional e econômica. Portanto, a análise incorpora as condições da vida econômica e social a que esses sujeitos estão submetidos.

O artigo está organizado em cinco seções,sendo essa primeira de caráter introdutório. Na segunda, se explicita o horizonte teórico-analítico utilizado na investigação. Nele, se argumenta que o entendimento da noção de vulnerabilidade possui, antes de mais nada, uma dimensão social mediada pelo funcionamento da estrutura institucional, permitindo que se compreenda de maneira mais apropriadaa diversidade de respostas diferenciais, sobretudo, aquelas mobilizadas pelos agricultores em ambientes rurais.

Na seção que segue,são detalhadoso panorama da região e os procedimentos metodológicos que foram empregadosna investigação. Na quarta seção são apresentadas as principais características das estratégias e lógicas de práticas produtivas dos agricultores familiares identificados no estudo. Na última seção, são elaboradas as considerações finais.

\section{Os sentidos da noção de vulnerabilidade associadas às mudanças ambientais}

Há uma crescente atenção dada a caracterização e o enquadramento atribuídos à noção de vulnerabilidade diante das transformações impostas ao ambiental ao longo do período pós Revolução Industrial. O principal 
motivo é que as distintas perspectivas teóricas acabam balizando práticas políticas muitas vezes antagônicas (O’Brien, Eriksen, Nygaard, \& Schjolden, 2007).A abordagem mais usual, nesse caso, coloca a vulnerabilidade como sendo o resultado residual negativo da exposição física, sobretudo em razão de uma compreensão limitada e muitas vezes equivocada dos riscos e dos perigos que têm sua origem na natureza. Há uma ênfase nessa perspectiva pela busca de informações que ofereçam um entendimento mais aguçado da dinâmica das ameaças e os estressores ambientais, na medida em que estes são entendidos como os causadores diretos das situações que podem levar à uma situação de vulnerabilidade.

O objetivo, com a projeção de cenários futuros prováveis das condições dos fatores naturais, é reduzir os impactos provocados com soluções estruturais de engenharia. Ou seja, há uma preocupação na gestão dos elementos naturais, apoiada em modelos preditivos de seu comportamento. Ainda que se reconheça que houve um significativo avanço para aprimorarseu caráter e importância enquanto instrumento para avaliar os resultados nas tomada de decisões em curto prazo, esse tipo de abordagem parece fazer pouco sentido diante da diversidade das respostas mobilizadas pelas sociedades humanas e pelos indivíduos frente a esses fenômenos (Burton, 1997). Isso não significa que avaliações sobre os limites físicos do ambiente natural não sejam importantes e não devam ser considerados, mas não se pode perder de vista que as pessoas reagem sob múltiplas vias e formas em relação aos sinais ambientais e não simplesmente a partir de uma relação causal.

Adger et al. (2008)ainda vão além:argumentam que apesar dessas formas serem interessantes e operacionais pela sua funcionalidade analítica e instrumental, elas ignoram aspetos essenciais comoa complexidade das formas e das maneiras como as sociedades se organizam. Essas posturas também desconsideram os valores e os conhecimentos que são construídos coletivamente ao longo da história, além das relações que permeiam os indivíduos, instituições e o Estado. Em outras palavras, confundem ou invertem as causas eos efeitos. Além do mais, a relação entre os possíveis impactos das mudanças ambientais e sua identificação enquanto fator de insegurança, que pode levar a uma situação de vulnerabilidade, não é necessariamente algo inequívoco e automático, como observam O’Brien et al. (2004). Essa característica está muitas vezes associada a uma questão de valores sociais e aspirações individuais e, portanto, de natureza subjetiva.É preciso considerar a vulnerabilidade sob uma ótica expandida, a partir das conexões espaço-temporais operando em diferentes escalas e processos que, muitas vezes, são aleatórios e não lineares (Turner II et al., 2003).

Portanto, há uma explícita divergência no que tange a centralidade do fator determinante da vulnerabilidade apresentada nessa investigação e a usualmente utilizada nas análises desenvolvidas a partir da projeção de cenários. Há o deslocamento de uma abordagem que se concentranos elementos externos, para uma em que se privilegia o elemento interno, ou seja, 
os fatores que condicionam a capacidade de resistir aos riscos ou adaptarse a uma mudança generalizada do ambiente (Prowse \& Scott, 2009). Sugerese assim que a vulnerabilidade não pode ser avaliada em função do comportamento atual ou mesmo futuro dos estressores biofísicos, essencialmente contingenciais, visto que ela é fundamentalmente determinada por fatores políticos e sociais. Isso implica estabelecer uma conexão conceitual entre a vulnerabilidade e anoção seniana de funcionamento dos intitulamentos, por serem esses os fatoresque realmente condicionam a capacidade das famílias na concepção de estratégias de subsistência para lidar com choques, especialmente as que vivem nos espaços rurais(Berman, Quinn, \& Paavola, 2012; Sen, 1999).

Uma mudança repentina em um dos elementos da estrutura dos elementos internos ou externos pode transformar radicalmente as condições que influenciam a resiliência e a capacidade adaptativa e assim, provocar uma alteração da vulnerabilidade dos indivíduos ou sociedades (Hulme \& Shepherd, 2003). Por essa razão, a análise do funcionamento do quadro institucional é um componente central para avaliar a vulnerabilidade, na medida em que as oportunidades e as perspectivas das pessoas são dependentes da variedade e da diversidade de instituições que existem e do modo como funcionam no local (Sen, 2009). Dito demaneira distinta, elas permeiam todo o tecido social e, por isso, moldam as principais características do sistema econômico e a estrutura e a distribuição de ativos.

Assim, um distúrbio no sistema natural não conduz, necessariamente, a uma situação de vulnerabilidade. A rigor, a condição de reagir e/ou adequar-se ou mesmo transformar-se diante de uma mudança permanente, ou seja, sua resiliência,é dependente da habilidade e da possibilidade que as pessoas possuem para produzirem as respostas que são inerentes a um contexto de mudanças, muitas inesperadas, que ocorrem no ambiente.Todavia, é preciso observar que ela não se restringe meramente à capacidade de absorver perturbações e se reorganizar. É bastante pertinente que se incorpore uma análise dos processos de aprendizagem que acontecem ao longo das mudanças,como lembram muito bem Adger et al. (2011).

Essa característica, em que a noção de resiliência incorpora a ideia de aprendizagem ou transformabilidade, também é apontada por Folke (2006) como fundamental ao se analisar a vulnerabilidade. A principal razão, apontada por ele, reside no fato de haver uma tendência atual na implementação de medidas de adaptação em que não há uma ponderação se realmente elas ajudam a controlar a vulnerabilidade.Como advertem Eriksen et al. (2011), nem todas as medidas que intencionam promover um processo de adaptação são essencialmente sustentáveis. Há inúmeros estudos empíricos que demonstram que valores e interesses diferentes afetam as estratégias que são priorizadas nessas ações, implicando na criação de externalidades, tanto ambientais quanto sociais, em termos de efeitos e consequências negativas. 
Por conseguinte, é preciso atribuir uma atenção maiorna avaliação da melhoria nas condições de transformabilidade do sistema do que a dedicada simplesmente aos processos de adaptação mobilizados diante de uma situação atual. Alguns estudiosos enfatizam que essa propriedade deva ser compreendida como a capacidade dos indivíduos de criarem um sistema essencialmente novo e original quando as estruturas ecológicas, econômicas ou sociais já não se apresentarem mais sustentáveis (Walker, Holling, Carpenter, \& Kinzig, 2004).Assim sendo, os processos de aprendizagem, que consistem na qualidade de combinar as experiências e os conhecimentos acumulados, oferecem elementos que permitem um melhor ajustamento das respostas às mudanças dos fatores externos e/ou internos e um melhor controle dos fatores que podem conduzir a uma situação de vulnerabilidade (Folke et al., 2010).Equivale a dizer também que há um processo de co-evolução entre os sistemas social e natural.

Desse modo, a vulnerabilidade não pode ser tratada e avaliada somente em termos do controle e do respeito, ou não, aos limites biofísicos. Há, portanto, um processo de "encaixe" entre os sistemas sociais e ecológicos envolvido nas ações de adaptação ou de enfrentamento, o que em si mesmo representa também um processo reflexivo para conceber as mudanças no ambiente,e não meramente uma ação instrumental e mecânica.

\section{Os caminhos para a formação da agricultura familiar no Alto Guaporé}

Localizada na mesorregião sudoeste mato-grossense, dentro dos limites da área da Amazônia Legal brasileira, a regiãodo Alto Guaporé apresenta enquanto característica natural o fato de ser uma área de transição entre os biomas do Pantanal Mato-grossense, o Cerrado e a Floresta Amazônica e está em uma faixa de fronteira com o país vizinho, a Bolívia.

Ainda que o processo de ocupação não indígena da região estivesse, num primeiro momento, diretamente relacionado com a exploração aurífera do século XVIII e a política de expansão territorial promovido pela coroa portuguesa, ele ocorreu de modo mais efetivo somente com a migração de pessoas de várias localidades do país nos primeiros anos da década de 1960, após o início da abertura da rodovia que liga a capital do estado de Mato Grosso, Cuiabá,à de Rondônia, Porto Velho. No entanto, tal processo teve uma característica que a diferenciava daquela observada em grande parte das áreas de fronteira agrícola na Amazônia. Enquanto nessas predominavam ações dirigidas pelos poderes públicos em projetos privados de colonização, a ocupação das terras na região do Alto Guaporéocorreu de maneira espontânea, ocasionado por uma espécie de vácuo criado pela ausência ou omissão frequente do Estado. 


\section{Figura 1}

\section{Mapa da localização da região do Alto Guaporé (MT), Brasil.}

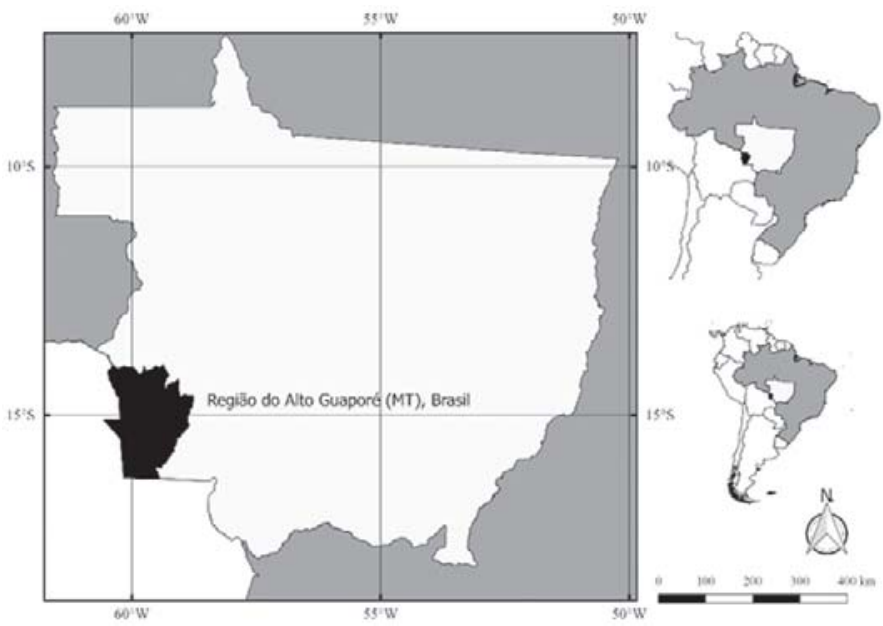

Fonte: Elaborado pelo autor (2017).

Marcado pela concessão indiscriminadade porções significativas das terras indígenas e públicas às empresas agropecuárias e profissionais liberais de outras regiões do país, frequentemente associada aos interesses político-partidários, acabou resultando em um mosaico de alta concentração fundiária, com a conivência do poder público. Não raro, elas aconteciam sem a sua demarcação física ou mesmo com a criação de documentos falsos, ação conhecida como grilagem. Relatos da existência de titulação de extensas áreas de terras superiores às disponíveis, com uma multiplicidade de registros que se sobrepunham, ou ainda a tomada de posse pelos ocupantes de lotes significativamente superior aos originalmente adquiridos explicam como essas práticas deram origem a uma imensa confusão nos cadastros de imóveis rurais em Mato Grosso e que resultou em várias ações de disputas marcadas pela violência.

É importante notar que o objetivo inicial da apropriação era a extração de madeira. Posteriormente, se procedia à derrubada manual das florestas para implantação de pastagens, o que passou a demandar a contratação de um contingente maior de mão de obra temporária, fazendo com que a região do Alto Guaporé se convertesse de um lugar de passagem e ponto de apoio amilhares de pessoas sem empregos e terras (que originalmente se direcionavam ao estado de Rondônia)em destino final, ao longo das décadas de 1970 e 1980. 
Entretanto, a oferta deempregos não era suficiente para absorver toda essapopulação que muitas vezes permanecia na região pelo fato de não ter sido contemplada pela colonização estatal em outras localidades, e impulsionou um movimento, por parte dessa, de ocupação das grandes áreas de terras que formalmente eram consideradas como devolutas e não tituladas. Todavia, a formação da agricultura familiar na região não está associada exclusivamente a essa ação. A postura de silencia ou omissão do Estado no cumprimento e execução das normas legais preconizadas para o ordenamento fundiário, associada à percepção de fragilidade de mobilização coletiva dos grandes proprietários e sua ausência na propriedade por longos períodos, estimularam igualmente a adoção de uma estratégia de invasão de terras em áreas em que havia contestações de titularidade entre latifundiários

Ou seja, a geração de um contingente de pessoas na condição de posseiros ou pequenos proprietários, que passou a ser verificadano Alto Guaporé,era resultado de uma situação social momentaneamente criada como efeito indireto da política nacional de ocupação da região amazônica.Os posseiros ocupavam a terra, derrubavam a mata, plantavam a roça, construíam seus barracos, abriam os limites dos lotes e o acesso a eles e dessa maneira, ao tornarem a área produtiva com o plantio de alimentos para garantir a manutenção de suas famílias, a ação de invasão da terra ganhava legitimidade e, paralelamente, estabelecia o direito de ser considerado posseiro. Assim, a dinâmica da formação de uma significativa agricultura familiar na região do Alto Guaporé pode ser mais bem compreendida, num primeiro momento, a partir de uma ótica associada à noção de uma "frente de expansão" (Martins, 2009). A ocupação de pequenas porções de terra buscava fundamentalmente viabilizar a própria subsistência mantendo a força de trabalho familiar e portanto, ela possuía muito mais um valor de uso do que de uma mercadoria.

Contudo, é evidente que essa estratégia quase nunca foi pacífica. Ela foi marcada por inúmeras situações de conflitos em que se recorreu ao uso da violência entre posseiros e pistoleiros ou seguranças, como eram denominados pelos latifundiários. Uma das formas de resistência utilizadas foi a instauração de uma espécie de rede familiar ou pela proximidade do local de origem nas ocupações diante da passividade estatal. Assim, haveria maior segurança em, ao estimularem situações de conflitos pela terra, propiciar as condições que poderiam levar aos seus ocupantes se tornarem reconhecidamente proprietários dela. O motivo para tal estratégia é queo Estatuto da Terra (BRASIL, 1964) reconhecia o direito da posse e indicava sua imediata desapropriação por interesse social quando ocorriam situações de tensão na disputa e existindo um número expressivo de famílias produzindo nas áreas. Seu objetivo era, portanto, regulare, se possível, conter os focos de tensão social que surgissem em razão da ausência de formalização dos direitos da terra que envolvia disputas territoriais, sobretudo em áreas de fronteira(Morena \& Higa, 2005).

Portanto, instigar o Estadoa regularizar uma área ocupada foi um mecanismo utilizado para fazê-lo reconhecer a legitimidade da ação 
empreendida pelos posseiros, mesmo valendo-se de uma situação conflituosa e violenta. Servia também para pressioná-lo na adoção de medidas que pudessem resultar em novos projetos de assentamentos. Desse modo, a ocupação de áreas e a criação de situações que ameaçavam ou abalavam a ordem social consistiam em uma estratégia de provocação deliberada com o intuito de uma ação de interferência do aparelho estatal, através de seu aparato institucional, no espaço rural. Foram várias as situações de enfrentamento provocadas pelos posseiros na região do Alto Guaporé (MT) que apontam para o uso desse mecanismo de enfrentamento, mesmo durante a vigência do regime militar que imperava no país.

Mas, é preciso salientar que o funcionamento do quadro institucional que moldou a forma de ocupação da terra na região também implicou uma profunda transformação no ambiente natural. Um primeiro aspecto que precisa ser observado é que a ação de delimitar uma área, seguido pela derrubada da mata para iniciar o plantio da roça e a construção de um local de moradia para assegurar a posse, sempre foi entendida como um investimento por parte dos agricultores em toda área da Amazônia Legal. No entanto, os posseiros, em geral, eram trabalhadores descapitalizados, ou seja, não possuíam os recursos financeiros necessários para viabilizar o início de sua produção na terra e para os investimentos emergenciais em infraestrutura.

Como a omissão da ação estatal inibiaa possibilidade de acesso aos recursos públicos, a estratégia mais usual para financiar as primeiras atividades agrícolas nesses lotes foi recorrer à atividade da extração de madeira. $\mathrm{O}$ fato de haver uma persistente morosidade e muita incerteza nos processos de regularização fundiária da propriedade da terra também contribuiu para que muitos posseiros efetuassem uma exploração indiscriminada de madeira na tentativa de compensar as despesas executadas para assegurar a posse da terra. Estabeleceu-se assim uma complexa aliança entre agricultores familiares, ou posseiros à época, e madeireiros, que impactou profundamente o meio natural local.Atualmente, nos 2.651 estabelecimentos rurais da agricultura familiar na região, que ocupam uma área equivalente a 162.613 hectares, apenas 6.022 são de matas e/ou florestas naturais destinadas à preservação permanente ou reserva legal(IBGE, 2009).

Desse modo, o que se pretender sublinhar é que os resultados ambientais da forma de ocupação da terra estão vinculados aos processos de decisão do uso da terra que ocorrem em nível de família e são o resultado das estratégias de subsistência mobilizadas por esses para se adaptar ou enfrentar um contexto social e institucional marcado por importantes interações entre as diferentes escalas e níveis, ainda que se admita que elas sejam noções heurísticas utilizadas para organizar a compreensão do mundo e das relações e interações nele existentes. Ou seja, não se pode perder de vista a noção de que a ação humana, as estruturas sociais e os sistemas naturais se interligam e, portanto, não há um melhor nível ou escala de caracterização e gestão das questões ambientais. Isso seria uma solução 
parcial e uma tentativa desprovida de possibilidades de sucesso na identificação das características e barreiras que modelam a vulnerabilidade e os fatores que reforçam a resiliência da agricultura familiar, como se pretende demonstrar na análise a seguir.

\section{Metodologia utilizada e a discussão dos resultados de pesquisa}

A escolha do recorte da investigação tomou como lócus os municípios de Conquista D’Oeste, Nova Lacerda, Pontes e Lacerda, Vale de São Domingos e Vila Bela da Santíssima Trindade e contou com um universo empírico de oito famílias, que tivessem como característica preponderanteaorganização da exploração agrícolaser essencialmente formada mão-de-obra da própria família e cuja propriedade não superasse o limite legalmente estabelecido(BRASIL, 2006). A definição dosentrevistados nesse estudo foi do tipo não probabilística intencional, que consiste em uma escolha não aleatória, ou seja, os indivíduos são intencionalmente escolhidos pelo fato de serem detentores de elementos ilustrativos do universo escolhido, e contou com o auxílio de informantes-chave, como os profissionais que prestam assistência técnica governamental (Creswell, 2010; Richardson, 2009).

Na coleta de dados, o principal instrumento de pesquisa utilizado foi a entrevista presencial, valendo-se de um roteiro semiestruturado que continha perguntas acerca da ocupação e das características grais da propriedadee da família, bem como de suas condições de sociais, a forma e a origem da renda familiar e os aspectos considerados importantes no funcionamento de aparato institucional. Em outras palavras, ele foi elaborado buscando explicitar as condições os fatores que condicionam a formação de uma situação de vulnerabilidade. O conjunto dos atributos que formam o meio natural de uma região, como a sua configuração,diversidade e disponibilidade, são importantes para determinar como as famílias mobilizam certas estratégias produtivas no intuito de garantir sua sobrevivência. Adicionalmente ainda, as informações julgadas como relevantes, e que de algum modo pudessem auxiliar na investigação, foram registradas em um diário de campo. As anotações são compostas de observações não contempladas pelo roteiro da entrevista, geralmente colhidas das conversas informais antes ou depois da sua aplicação, ou então de comentários de pessoas não entrevistadas formalmente, como outros membros da família ou vizinhos.

Como a capacidade adaptativa, ou de enfrentamento, está diretamente relacionada com a habilidade de um sistema para ajustar as mudanças no ambiente ou para lidar com as consequências, sejam elas esperadas ou não, e a sensibilidade refere-se ao grau em que um sistema irá responder a essas transformações, de forma positiva ou negativa, ao passo que a exposição se refere ao grau de estresse empreendido sobre uma determinada unidade 
de análise, a abordagem desenvolvida nessa investigação representa uma interpretação, da tipologia desenvolvida por McCarthy et al. (2001). A finalidade é mostrar como os diferentes fatores condicionam, e em última instância, modelam as situações de vulnerabilidade. Portanto, a vulnerabilidade é, em última instância, constituída por meio da combinação dos atributos da capacidade de adaptação e de enfrentamento aos processos de mudança do ambiente. Em razão disso,o objetivo não foi a construção de qualquer medida que intente mensurar tais características. A finalidade é reconstituir a trajetóriade como os atributos que compõem o sistema natural, como a qualidade dos solos e a disponibilidade de acesso aos mananciais hídricos, bem como fatores relacionados à questão fundiária, demográfica e do meio socioeconômico, condicionam, ao facilitar ou dificultar a definição das escolhas e nas estratégias adaptativas mobilizadas pelos agricultores respostas adaptativas em termos das práticas produtivas diante das mudanças ambientais contemporâneas.

\section{Explorando evidências da vulnerabilidade às mudanças ambientais na região do Alto Guaporé (MT)}

Embora se reconheça a importância da manutenção de um equilíbrio adequado dos elementos e dos ciclos do meio natural, não é a expectativa do risco e da exposição aos impactos dessas transformações que pode amparar uma avaliação da vulnerabilidade.Isso implicaria privilegiar uma análise das razões aparentes e imediatas, ignorando os fatores que condicionam sua produção. As diferentes respostas observadas pelos mais diversos e diferentes grupos da sociedade demonstram que é preciso envolver na análise as causas estruturais da vulnerabilidade. Ou seja, os fatores de exposição, como a localização, não podem ser confundidos com os elementos causais que modelam a forma de acesso aos elementos que motivam essas situações.

Por essa razão, é importante avaliar e compreender adequadamente os processos sociais e econômicos que moldam e condicionam a resposta adaptativa dos indivíduos e grupos sociais frente às mudanças do ambiente. Portanto, para compreender como se caracteriza a vulnerabilidade, sobretudo daquelas famílias que residem em ambientes rurais, é preciso observar os mecanismos pelos quais as pessoas modificaram ou promoveram as adaptações na sua maneira de garantir sua subsistência diante das circunstâncias ou tendências nos fatores de risco, à medida que eles surgem. Em outras palavras, é preciso analisar e entender a evolução do conhecimento da dinâmica local sobre os sistemas ecológicos desenvolvidos e transmitidos de geração em geração enquanto aprendizado da trajetória da relações dos seres vivos com o ambiente para garantir sua subsistência (Reinert et al., 2009). 


\section{A subsistência a partir de rendas de transferências sociais: as aposentarias rurais}

Vários estudos demonstram que é relativamente frequentehá algum tempo, tanto em países desenvolvidos quanto naqueles que ainda estão em desenvolvimento, que os mecanismos utilizados para suprir as necessidades de subsistência dos agricultores não mais se resumem exclusivamente à atividade agrícola (FAO, 2015; Mertz et al., 2011; Reardon, Berdegué, \& Escobar, 2001). A ampliação desse tipo de estratégiano meio rural tem sido apontada como importante pela contribuição que vem exercendo para o surgimento de um novo cenário que inclui oportunidades de ocupação para a população residente nessas áreas. É evidente que há uma enorme diversidade de níveis e arranjos, que geralmente estão em função das condições disponíveis e capazes de serem exploradas e/ou mobilizadaspelo agricultor, tanto do meio natural quanto do social.Como o campo de domínio das iniciativas pautadas nesse tipo de ações é significativamente amplo, o grupo mais apropriado para uma abordagem em que as causas sociais são postas no cerne da análise da vulnerabilidade, parece razoável centrar-se naqueles que dependem das transferências de renda na forma de aposentadorias rurais, sobretudo porque são famílias constituídas por pessoas idosas. Até porque foi a lógica mais usual identificada no estudo dentre os que garantem a subsistência familiar a partir de rendas não agrícolas.

É indubitável a importância dessa forma de proteção social enquanto instrumento de redução e de exposição desses agricultores às situações que potencializam sua vulnerabilidade, pois mudanças inesperadas na economia ou ainda obstáculos decorrentes de limitações físicas, como doenças repentinas em razão da idade avançada, podem implicar prejuízos momentâneos ou mesmo permanentes e que podem implicar na perda dos meios que garantem a subsistência.Nessa direção, na maioria das vezes os agricultores apontam que a precariedade nas condições de trafegabilidade que as estradas apresentam, principalmente nos períodos de maiores precipitações pluviométricas, e as longas distânciaslimitam seu deslocamento para acessarem um serviço minimamente adequado de assistência médica e/ou à infraestrutura educacional. Em outras palavras, à medida que as distâncias dos centros urbanos aumentam, eles são fatores que muitas vezes provocaram a privação da capacidade de mobilizar um conjunto de recursos vitais, expondo-os aos mais variados tipos de riscos que, pela incapacidade de superar as externalidades negativas produzidas pelos sistemas ambiental e social, fazem uma enorme diferença na vida cotidiana dessas pessoas, limitando assim a capacidade de enfrentarem ou adaptarem-se de maneira adequada.

Adicionalmente, uma outra condição geralmente associada à avaliação da vulnerabilidade de qualquer grupo social, mas que ganha contornos mais destacados junto a esses, são os efeitos do nível educacional sobre a saúde. Pessoas com menoresníveis de educação formal, como observado em praticamente todos os que integram esse grupo,geralmente 
apresentam uma dificuldade substancialmente maior na percepção dos fatores associados às condutas consideradas mais saudáveis, que implicam índices menores de risco de morte causados por problemas de saúde. Ou seja, pessoas com baixa escolaridade apresentam uma probabilidade bastante superior de morrerem em consequência de problemas associados a saúde ante aquelas identificadas com ensino médio ou superior, sobretudo em ambientes onde o acesso a esse recurso é bastante limitado, como observado nessa investigação(Baker et al., 2011). Em outras palavras, os processos de alfabetização dos indivíduos e o aprimoramento de suas competências numéricas produzidas pela educação formal, aperfeiçoam as aptidões gerais e as habilidades cognitivas das pessoas, o que faz com que haja uma melhor compreensão e capacidade de processar e assimilar as informações para resolver problemas que requerem o uso do pensamento abstrato e do raciocínio lógico. Essa característica é considerada como fundamental por alguns estudiosospara conseguirem responder positivamente quando se encontram numa situação de emergência e/ou de risco (Schnell-Anzola, Rowe, \& LeVine, 2005).

Esse aspecto fica evidenciado ao se contatar que na maioria das propriedades, onde se constatou um acesso restrito à educação formal, não é possível constar qualquer tipo de áreas remanescentes da cobertura florestal original. Por outro lado, é frequente se observar áreas que podem ser classificadas como degradadas, em maior ou menor proporção. A presença dessas características geralmente está associada a uma condição que levou a uma paulatina intensificação no uso do sistema produtivo adotado, sem, no entanto,haver uma atenção na utilização de formas de manejo que pudessem manter e/ou conservaras propriedades físicas e químicas dos solos. Nenhum dos agricultores fez qualquer tipo de análise da composição de sua fertilidade, nem tampouco qualquer tipo de procedimento de adubação. Os relatos colhidos na investigação sugerem que nem mesmo a implementação de medidas práticas preventivas que evitassem a exposição desses locais aos processos erosivos foi implementada ao longo do tempo em que ocupam a área.

Como se percebe nesse caso,a educação se constitui em uma importante barreira que incrementa a vulnerabilidade social. O acesso limitado ao conhecimento formal restringiu a capacidade de planejar o futuro e melhorar a alocação de recursos e, assim, determinar as prioridades necessárias para adaptar-se às novas condições para garantir seus meios de subsistência familiar.Esse aspecto é realçado quando se constataque uma dinâmica de redução no tamanho da propriedade originalmente ocupada équase sempre atribuída a uma situação de extrema necessidade para garantir a reprodução material da família. Portanto, embora possuam nas transferências de renda dos programas de proteção social a fonte mais importante e determinante na manutenção familiar, muitas vezes elas são conseguem cumprir adequadamente tal finalidade.

Todavia, essa situação de vulnerabilidade não as torna "vítimas passivas” diante das circunstâncias adversas, como sublinha Tschakert 
(2007). Elas respondem estrategicamente recorrendo a várias lógicas de composições distintas de rendas que lhes permita complementar tais ganhos. A maneira mais usual é a conversão ao aluguel ou arrendamento de parte da área destinada à exploração produtiva realizada por outrem, sem, no entanto, abdicar de uma lógica de manter uma parcela da propriedade destinada à criação de pequenos animais e/ou umas poucas cabeças de gado de leite e/ ou corte, utilizadas primordialmente para o autoconsumo e o abastecimento das famílias dos filhos. Eles justificam que ao produzirem e terem disponíveis uma parte dos alimentos consumidos na manutenção cotidiana, há um substancial incremento na sua segurança alimentar. Ao mesmo tempo, melhora a capacidade de responder positivamente a uma situação que comprometa a vulnerabilidade dessas famílias, pois, garante-lhes autonomia sobre uma dimensão-chave para sua reprodução material, que é o abastecimento alimentar de seus integrantes.

Contudo, a constatação na redução do tamanho da propriedade observada nesses casos nem sempre pode refletir objetivamente uma fragilidade em sua capacidade de garantir a subsistência familiar. Ou seja, nem sempre pode ser avaliado como uma manifestação da vulnerabilidade.Em certos casos, ela consiste de uma ação deliberada em que própria família procura estabelecer uma espécie de "controle na trajetóriada sucessão" na propriedade. Ou seja, há um "repasse” de parte da área original aos filhos que fixaram residência no meio rural com o claro objetivo de resguardar o patrimônio, geralmente conquistado com a superação de inúmeras dificuldades. Não raro,isso incluiu situações de conflito e o uso da violência pela disputa da terra e um ambiente tipicamente repressivo de fronteira, visto que a maioria são os proprietários de primeira geração do local.Isso significa que a lógica empreendida nesses casos pelos agricultores, na tentativa de manter o tamanho original da área, transferindoa, quer seja por um processo formal de venda facilitada,ou então pela simples divisão de parte da área entre os membros que sejam seus sucessores diretos, opera a partir do estabelecimento de um nexo que inclui elementos de caráter simbólicos e culturais, transmitidos, retransmitidos e atrelados não somente aterra, como à sua própria trajetória de agricultor e de sua família no local.

Como é possível perceber, a produção de respostas às mudanças no ambiente, não emerge como um resultado contingencial de ações tomadas e construídas de maneira descontextualizada ao longo do tempo e do espaço. A ação de subdividir as propriedades, destinando-as aos filhos ou seus herdeiros, pode ser compreendida como uma articulação que objetiva a apropriação e a manutenção dos elementos e significados simbólicos associados por esses agricultores junto ao seu local de vivência. Eles são, em última instância, manifestações do conjunto de elementos do meio natural e social e seus significados subjetivos. Em outras palavras, essa ação empreendida pelos agricultores implica em reconhecer as múltiplas formas e perspectivas das relações que o homem estabelece com o ambiente biofísico (Jasanoff, 2010). 
Esse aspecto é particularmente importante quando se avalia a vulnerabilidade. Evidências empíricas sugerem que na medida em que há uma perda no reconhecimento de identidade com o local e suas dinâmicas biofísicas, se interfere na forma da ligação que os indivíduos estabelecem com o ambiente e, consequentemente, fragiliza-se o entendimento de como ocorrem os processos das mudanças no ambiente, sobretudo no meio natural(Lai \& Kreuter, 2012). Folke (2006)sugere que a perda dessa conexão pode provocar o comprometimento de qualidades importantes no processo de ajustamento às mudanças ambientais, como a capacidade de renovação, de reorganização e de desenvolvimento, que ajudam na redução da incerteza informacional e normativa. Ou seja, o seu gradativo desaparecimento pode comprometer a capacidade adaptativa das pessoas às mudanças ambientais ao torná-las menos resilientes.

Outro aspecto que merece atenção ao se analisar a vulnerabilidade social desse grupo de agricultores é o fato de se integrarem socialmente por uma participação meramente formal nas atividades dos sindicatos dos trabalhadores rurais. Isso fragiliza sua adaptabilidade, visto que ela é condicionadafortemente pela capacidade dos agricultores e de suas famílias deacessar as principais informações que potencialmente ajudam na maneira de auto organizar-se coletivamente(Adger, 2000). Ou seja, ao dispensarem uma participação mais ativa nesses espaços, passa a haver uma maior limitação em um acesso mais apropriadono entendimento dos problemas a serem enfrentados e, por consequência, como encontrar maneiras de produzir respostas que possam levar àsua superação. Não há a incorporação daquilo que essencialmente caracteriza um processo de aprendizagem, e se não há como transmitir as lições aprendidas com as experiências coletivas do cotidiano há uma dificuldade maior na precaução aos riscos das mudanças que ocorrem no ambiente(Poumadère, Mays, Le Mer, \& Blong, 2005).

Portanto, não há como deixar de reconhecer que uma população pouco instruída, envelhecida e, adicionalmente,apresentando umcomportamento apático diante dos processos de mobilização coletiva e que éobjeto de políticas públicas com características que podem ser classificadas como compensatórias, possui um alcance limitado na dinamização econômica das zonas rurais. Mas, ainda assim, é possível avaliar que os programas baseados em transferência de rendas em ambientes rurais apresentam resultados bastante positivos do ponto de vista da proteção social e, por consequência, uma ação que impacta positivamente na redução da exposição dessas famílias às diferentes situações de vulnerabilidade.

\section{Considerações finais}

Em razão da localização geográfica, que envolve uma área que conecta três importantes biomas do país, a região do Alto Guaporé, no sudoeste do estado de Mato Grosso, no Brasil, abriga uma diversidade em seu sistema natural que a torna extremamente singular e cuja dinâmica de ocupação modificou, e continua modificando,imensamente a capacidade de 
suporte desses em continuar se mantendo sustentável em suas funções ecossistêmicas.Uma das consequências diretas desse desequilíbrio é o fato de converter-se num aspecto que potencialmente afeta as condições de vida dos habitantes nessa área, sobretudo,dos que residem no meio rural.Em termos analíticos, como resultado dessa crescente exposição físicaaos riscos e aos perigos que têm sua origem na natureza, tradicionalmente, haveria uma avaliação que tais circunstâncias comprometeriam a resiliência dessas pessoas, tornando-as mais vulneráveis.

Todavia, imaginar que é possível avaliar a qualidade e a robusteza da forma de organizar a vida cotidiana das pessoas para superar ou contornar as barreiras que fragilizam a sua situação de vulnerabilidade ou de resiliência, sem considerar a sua trajetória e as condições do funcionamento do quadro institucional é limitar-se às consequências e ignorar suas raízes. Isso porque,como se procurou demonstrar, elas não são passivas diante de tais conjunturas. Elas buscam e articulam alternativas que objetivam enfrentar e/ou adaptar-se às novas condições como forma de superar as limitações que lhes são impostas, tanto pelo meio natural quanto pelo social. Para tanto, valem-se deestratégias heterogêneas e combinam distintas lógicas para viabilizar e/ou melhorar suas condições de vida. Imaginar que as pessoas estão igualmente expostas aos potenciais riscos e perigos, que omeio natural oferece,não parece ser uma perspectiva muito persuasiva em termos de elementos suficientes para a explicação e superação das principais problemáticas associadas às mudanças ambientais contemporâneas, nem tampouco contribuir com os estudos rurais para elucidar a diversidade com que as pessoas ou grupos acessam os recursos e conseguem articulá-los.

É preciso ir além das perspectivas que se estruturam no paradigma da confiança no progresso técnico e na racionalidade científica instrumental, cujos esforços ficam restritos à identificação e a domesticação de possíveis efeitos dos distúrbios. Até porque estes, não necessariamente conduzem a uma situação de vulnerabilidade. Eles podem, inclusive, transformá-los em oportunidades para a criação de inovações.Isso implica reconhecer que os processos adaptativos mobilizados para responder a tais condições nunca são homogêneos. Eles são, invariavelmente, influenciados por fatores que incluem as condições sociais, as econômicas e as institucionais que lhe são específicos em termos, não somente espaciais, como também, temporais. Desta feita, extrapolam a ideia de serem uma resposta intuitiva, exclusivamente condicionada ao comportamento dos elementos da natureza, ainda que se reconheça sua importância e não se ignore sua influência.

Tais processos precisam ser encarados como mecanismos deliberados de ajustamento, que são empregados e desenvolvidos ao longo do tempo para suplantar os fatores que poderiam, eventualmente, implicar e levar a uma incapacidade de enfrentar ou adaptar-se às mudanças ambientais contemporâneas. É, em última instância, um processo de aprendizado, como se procurou demonstrar, que pode torná-los hábeis, ou não, que reflete sua capacidade de melhorar sua situação de 
vulnerabilidade e resiliência social em processos, tanto abruptos quanto prolongados de transformações no ambiente.

Em suma, esse artigo procurou demonstrar que a trajetória do processo recente de ocupação dessa região é acompanhada por uma significativa e profunda transformação antropogênica dos elementos que integram os sistemas natural e social. Assim,essa transformação não ocorreu de maneira fortuita, mas foi condicionada por um contexto social, econômico e institucional que induziu de maneira persistente uma contínua elaboração e produção de respostas que buscaram ser suficientemente robustas para enfrentar e/ou adaptar-se a cada nova situação.Ou seja, se demonstrou que a vulnerabilidade ou a capacidade de resistir e enfrentar ou de se adaptar desse grupo de famílias rurais às mudanças ambientais que ocorreram ao longo das últimas décadas, não são noções que refletem meramente a dimensão da sua exposição física. A capacidade desses indivíduos em se adequarem aosnovos cenários se modifica ao longo do tempo e é diferenciada entre os integrantes desse grupo, dependendo de sua posição institucional e econômica.

Portanto, ainda que a manutenção de um equilíbrio do meio natural seja importante e que a ideia de limiares nos componentes desse sistema não possaser ultrapassada seja atraente e se reconheça sua relevância, uma situação de vulnerabilidade não se configura pela probabilidade do risco e da exposição aos impactos dessas transformações. Isso seria limitar-se a uma tentativa de identificar as razões aparentes e imediatas e obscurecer as condições que estão subjacentes aos mecanismos de sua produção. Por esse motivo, houve uma atenção especial para uma análise que incorporasse as condições da vida econômica e social, além do funcionamento do ambiente institucional a que esses sujeitos estão submetidos, concentrando a atenção no entendimento das dimensões sociais dos processos de produção de respostas às mudanças ambientais contemporâneas, que muitas vezes são negligenciadas e mal compreendidas. 


\section{Bibliografia}

Adger, W. N. (2000). Institutional adaptation to environmental risk under the transition in Vietnam. Annals of the Association of American Geographers, 90(4), 738-758. https://doi.org/10.1111/00045608.00220

Adger, W. N. (2006). Vulnerability. Global Environmental Change, 16(3), 268-281. https://doi.org/10.1016/j.gloenvcha.2006.02.006

Adger, W. N., Brown, K., Nelson, D. R., Berkes, F., Eakin, H. C., Folke, C., ... Tompkins, E. L. (2011). Resilience implications of policy responses to climate change. Wiley Interdisciplinary Reviews: Climate Change, 2(5), 757-766. https://doi.org/10.1002/wcc.133

Adger, W. N., Dessai, S., Goulden, M. C., Hulme, M., Lorenzoni, I., Nelson, D. R., ... Wreford, A. (2009). Are there social limits to adaptation to climate change? Climatic Change, 93(3-4), 335-354. https://doi.org/ 10.1007/s10584-008-9520-z

Bai, X., van der Leeuw, S., O’Brien, K., Berkhout, F., Biermann, F., Brondizio, E. S., ... Syvitski, J. (2015). Plausible and desirable futures in the Anthropocene: A new research agenda. Global Environmental Change, 39, 351-362. https://doi.org/10.1016/ j.gloenvcha.2015.09.017

Baker, D. P., Leon, J., Smith Greenaway, E. G., Collins, J., Movit, M., Greenaway, E. G. S., ... Movit, M. (2011). The Education Effect on Population Health: A Reassessment. Population and Development Review, 37(2), 307-332. https://doi.org/10.1111/j.17284457.2011.00412.x

Berman, R., Quinn, C. H., \& Paavola, J. (2012). The role of institutions in the transformation of coping capacity to sustainable adaptive capacity. Environmental Development, 2, 86-100. https://doi.org/10.1016/ j.envdev.2012.03.017

Biermann, F., Abbott, K. W., Andresen, S., Backstrand, K., Bernstein, S., Betsill, M. M., ... Zondervan, R. (2012). Navigating the Anthropocene: Improving Earth system governance. Science, 335(6074), 1306-1307. https://doi.org/10.1126/science.1217255

BRASIL. (1964). Lei no 4.504, de 30 de novembro de 1964. Recuperado de http://www.planalto.gov.br/ccivil_03/leis/L4504compilada.htm

BRASIL. (2006). Lei $n^{\circ} 11.326$, de 24 de julho de 2006. Recuperado de http://www.planalto.gov.br/ccivil_03/_ato2004-2006/2006/lei/ 111326.htm 
Burton, I. (1997). Vulnerability and adaptive response in the context of climate and climate change. Climatic Change, 36(1/2), 185-196. https:/ /doi.org/10.1023/A:1005334926618

Costa, M. H., \& Pires, G. F. (2010). Effects of Amazon and Central Brazil deforestation scenarios on the duration of the dry season in the arc of deforestation. International Journal of Climatology, 30(13), 19701979. https://doi.org/10.1002/joc.2048

Creswell, J. W. (2010). Projeto de pesquisa: métodos qualitativo, quantitativo e misto ( $3^{\circ}$ ed). Porto Alegre, Brasil: Artmed.

D’Almeida, C., Vörösmarty, C. J., Hurtt, G. C., Marengo, J. A., Dingman, S. L., \& Keim, B. D. (2007). The effects of deforestation on the hydrological cycle in Amazonia: a review on scale and resolution. International Journal of Climatology, 27(5), 633-647. https://doi.org/ 10.1002/joc.1475

Ellis, F. (1998). Household strategies and rural livelihood diversification. Journal of Development Studies, 35(1), 1-38. https://doi.org/10.1080/ 00220389808422553

EMBRAPA, \& UNICAMP. (2008). Aquecimento global e a nova geografia da produção agrícola no Brasil. (E. Assad \& H. Silveira, Orgs.), EMBRAPA/UNICAMP. Brasília / Campinas, Brasil: Empresa Brasileira de Pesqusia Agropecuária - Embrapa / Universidade de Campinas Unicamp. Recuperado de http://www.embrapa.br/publicacoes/ institucionais/titulos-avulsos/aquecimentoglobal.pdf

Eriksen, S., Aldunce, P., Bahinipati, C. S., Martins, R. D., Molefe, J. I., Nhemachena, C., ... Ulsrud, K. (2011). When not every response to climate change is a good one: Identifying principles for sustainable adaptation. Climate and Development, 3(1), 7-20. https://doi.org/ 10.3763/cdev.2010.0060

FAO. (2015). The State of Food and Agriculture 2015 in brief: Social protection and agriculture: breaking the cycle of rural poverty, 1-13.

Fischer, J., Manning, A. D., Steffen, W., Rose, D. B., Daniell, K., Felton, A., ... Wade, A. (2007). Mind the sustainability gap. Trends in Ecology \& Evolution, 22(12), 621-624. https://doi.org/10.1016/ j.tree.2007.08.016

Foley, J. A., Asner, G. P., Costa, M. H., Coe, M. T., DeFries, R., Gibbs, H. K., ... Snyder, P. (2007). Amazonia revealed: forest degradation and loss of ecosystem goods and services in the Amazon Basin. Frontiers in Ecology and the Environment, 5(1), 25-32. https://doi.org/10.1890/ 1540-9295(2007)5[25:ARFDAL]2.0.CO;2 
Foley, J. A., DeFries, R. S., Asner, G. P., Barford, C., Bonan, G. B., Carpenter, S. R., ... Snyder, P. K. (2005). Global consequences of land use. Science, 309(5734), 570-574. https://doi.org/10.1126/ science.1111772

Folke, C. (2006). Resilience: The emergence of a perspective for socialecological systems analyses. Global Environmental Change, 16(3), 253-267. https://doi.org/10.1016/j.gloenvcha.2006.04.002

Folke, C., Carpenter, S., Elmqvist, T., Gunderson, L., Holling, C. S., \& Walker, B. (2002). Resilience and Sustainable Development: Building Adaptive Capacity in a World of Transformations. AMBIO: A Journal of the Human Environment, 31(5), 437-440. https://doi.org/ 10.1579/0044-7447-31.5.437

Folke, C., Carpenter, S. R., Walker, B. H., Scheffer, M., Chapin, T., \& Rockström, J. (2010). Resilience thinking: Integrating resilience, adaptability and transformability. Ecology And Society, 15(4), art. 20.

Gordon, L. J., Peterson, G. D., \& Bennett, E. M. (2008). Agricultural modifications of hydrological flows create ecological surprises. Trends in ecology \& evolution, 23(4), 211-219. https://doi.org/10.1016/ j.tree.2007.11.011

Gunderson, L., \& Folke, C. (2011). Tricky times. Ecology and Society, 16(4), art. 31. https://doi.org/10.5751/ES-04640-160431

Hardoon, D. (2017). An Economy for the 99\%: It's time to build a human economy that benefits everyone, not just the privileged few. Oxford. https://doi.org/10.21201/2017.8616

Hulme, D., \& Shepherd, A. (2003). Conceptualizing Chronic Poverty. World Development, 31(3), 403-423. https://doi.org/10.1016/S0305750X(02)00222-X

IBGE. (2009). @Sidra. Recuperado de http://www.sidra.ibge.gov.br/bda/ tabela/protabl.asp?c $=1112 \& \mathrm{z}=\mathrm{p} \& \mathrm{o}=2 \& \mathrm{i}=\mathrm{P}$

Jasanoff, S. (2010, maio 24). A New Climate for Society. Theory, Culture \& Society. https://doi.org/10.1177/0263276409361497

Lai, P., \& Kreuter, U. P. (2012). Examining the direct and indirect effects of environmental change and place attachment on land management decisions in the Hill Country of Texas, USA. Landscape and Urban Planning, 104(3-4), 320-328. https://doi.org/10.1016/ j.landurbplan.2011.11.007

Martins, J. de S. (2009). Fronteira: a degradação do outro nos confins do humano. São Paulo, Brasil: Contexto. 
Mertz, O., Mbow, C., Reenberg, A., Genesio, L., Lambin, E. F., D’haen, S., ... Sandholt, I. (2011). Adaptation strategies and climate vulnerability in the Sudano-Sahelian region of West Africa. Atmospheric Science Letters, 12(1), 104-108. https://doi.org/10.1002/asl.314

Morena, G., \& Higa, T. C. S. (2005). Geografia de Mato Grosso. Cuiabá, Brasil: Entrelinhas.

Nobre, C. A., Sellers, P. J., \& Shukla, J. (1991). Amazonian deforestation and regional climate change. Journal of Climate, 4(10), 957-988. https://doi.org/10.1175/1520-0442(1991)004<0957: ADARCC $>2.0 . \mathrm{CO} ; 2$

O’Brien, K., Eriksen, S., Nygaard, L., \& Schjolden, A. (2007). Why different interpretations of vulnerability matter in climate change discourses. Climate Policy, 7(1), 73-88. https://doi.org/10.3763/cpol.2007.0706

O’Brien, K., Eriksen, S., Schjolden, A., \& Nygaard, L. (2004). What's in a word? Conflicting interpretations of vulnerability in climate change research (No. 04). Environmental Research. Oslo - Norway.

Poumadère, M., Mays, C., Le Mer, S., \& Blong, R. (2005). The 2003 heat wave in France: Dangerous climate change here and now. Risk Analysis, 25(6), 1483-1494. https://doi.org/10.1111/j.1539-6924.2005.00694.x

Prowse, M., \& Scott, L. (2009). Assets and adaptation: an emerging debate. IDS Bulletin, 39(4), 42-52. https://doi.org/10.1111/j.17595436.2008.tb00475.x

Reardon, T., Berdegué, J., \& Escobar, G. (2001). Rural nonfarm employment and incomes in Latin America: Overview and policy implications. World Development, 29(3), 395-409. https://doi.org/10.1016/S0305750X(00)00112-1

Reinert, E. S., Aslaksen, I., Eira, I. M. G., Mathiesen, S. D., Reinert, H., \& Turi, E. I. (2009). Adapting to climate change in Sámi reindeer herding: the nation-sate as problem and solution. In W. N. Adger, I. Lorenzoni, \& K. O’Brien (Orgs.), Adapting to climate change: Thresholds, values, governance (p. 417-432). New York: Cambridge University Press.

Richardson, R. J. (2009). Pesquisa Social: métodos e técnicas (3ºd). São Paulo, Brasil: Atlas.

Rockström, J., Steffen, W., Noone, K., Persson, Å., Chapin III, F. S., Lambin, E. F., ... Foley, J. A. (2009). Planetary boundaries: Exploring the safe operating space for humanity. Ecology And Society, 14(2)

Schnell-Anzola, B., Rowe, M. L., \& LeVine, R. A. (2005). Literacy as a pathway between schooling and health-related communication skills: 
a study of Venezuelan mothers. International Journal of Educational Development, 25(1), 19-37. https://doi.org/10.1016/ j.ijedudev.2004.05.002

Sen, A. (1999). Pobreza e fome. Lisboa. Lisboa: Terramar. Recuperado de http://scholar.google.com/scholar?hl=en\&btnG= Search\&q=intitle:Pobreza+e+Fomes\#1

Sen, A. (2009). Desenvolvimento como liberdade. São Paulo, Brasil: Cia. das Letras.

Sumner, A. (2010). Global Poverty and the New Bottom Billion: What if Three-quarters of the World's Poor Live in Middle-income Countries? IDS Working Papers, 2010(349), 01-43. https://doi.org/10.1111/ j.2040-0209.2010.00349_2.x

Tschakert, P. (2007). Views from the vulnerable: Understanding climatic and other stressors in the Sahel. Global Environmental Change, 17(34), 381-396. https://doi.org/10.1016/j.gloenvcha.2006.11.008

Turner II, B. L., Kasperson, R. E., Matson, P. A., McCarthy, J. J., Corell, R. W., Christensen, L., ... Schiller, A. (2003). A framework for vulnerability analysis in sustainability science. Proceedings of the National Academy of Sciences of the United States of America, 100(14), 8074-8079. https://doi.org/10.1073/pnas.1231335100

Walker, B. H., Holling, C. S., Carpenter, S. R., \& Kinzig, A. P. (2004). Resilience, adaptability and transformability in social - ecological systems. Ecology And Society, 9(2), art. 5. Recuperado de http:// www.ecologyandsociety.org/vol9/iss2/art5/

Recibido:10.07.17

Aceptado: 01.08.18 